\title{
“Combined Off-Pump Mitral Valve Repair and Lung Malignancy Resection Through Left Thoracotomy"
}

\author{
Matteo Marro*1, Stefano Salizzoni' ${ }^{1}$, Paolo Lausi ${ }^{2}$, Walter Grosso Marra ${ }^{3}$, Davide Ricci ${ }^{1}$, Alessandro \\ Vairo $^{3}$ and Mauro Rinaldi ${ }^{1}$ \\ ${ }^{1}$ Department of Surgical Sciences, Division of Cardiac Surgery, Italy \\ ${ }^{2}$ Department of Surgical Sciences, Division of Thoracic Surgery, Italy
}

${ }^{3}$ Department of Medical Sciences, Division of Cardiology, Italy

*Corresponding author: Matteo Marro, San Giovanni Battista “Molinette” Hospital Corso Bramante 88-90, Torino, Italy

\begin{tabular}{|c|c|}
\hline ARTICLE INFO & ABSTRACT \\
\hline Received: 慧 April 25, 2019 & Transapical, off-pump, minimally invasive Neochord implantation is a technique that \\
\hline Published: 蔧 May 01, 2019 & $\begin{array}{l}\text { has been proven to be safe and effective in treating high-risk patients with degenerative } \\
\text { mitral regurgitation due to leaflet(s) prolapse and/or flail. The Neochord procedure char- }\end{array}$ \\
\hline $\begin{array}{l}\text { Citation: Matteo Marro, Stefano Saliz- } \\
\text { zoni, Paolo Lausi, Walter Grosso Marra, } \\
\text { Davide Ricci, Alessandro Vairo, Mauro } \\
\text { Rinaldi. "Combined Off-Pump Mitral }\end{array}$ & $\begin{array}{l}\text { acteristics allow to expand indications in selected patients in which standard surgery with } \\
\text { cardioplegic arrest of the heart and extracorporeal circulation should be avoided. These } \\
\text { cases represent the firsts reported of simultaneously treatment of mitral regurgitation } \\
\text { with off-pump NeoChord technique and lung malignancy resection by a left anterior small } \\
\text { thoracotomy. }\end{array}$ \\
\hline
\end{tabular}
Valve Repair and Lung Malignancy Resection Through Left Thoracotomy". Biomed J Sci \& Tech Res 17(4)-2019. BJSTR. MS.ID.003037.

Keywords: Mitral valve repair; Mini-invasive surgery; Lung malignancy; Combined surgery

\section{Introduction}

Transapical, off-pump, minimally invasive Neochord implantation is a technique that has been proven to be safe and effective in treating high-risk patients with degenerative mitral regurgitation (MR) due to leaflet(s) prolapse and/or flail [1-4]. The Neochord procedure characteristics allow to expand indications in selected patients in which standard surgery with cardioplegic arrest of the heart and extracorporeal circulation should be avoided. The procedure is performed using the NeoChord DS1000 system (NeoChord, Inc., Eden Praire, MN) under real-time guidance by transesophageal echocardiography (TEE). This technique can be used in new approaches for combined procedures [4].

\section{Case Reports}

A 72-year-old (patient A) and a 60-year-old (patient B) men came to our attention for dyspnea for severe MR due to the presence of severe P2 prolapse (Figures 1A-1D). Both patients had concomitant left inferior lung malignancy. The first, with history of thyroid carcinoma and previous atypical right lung resection for metastasis, presented three new left inferior pulmonary nodules (Figure 1E). The second had an adenocarcinoma in the same position, found during pre-operative CT scan for traditional on-pump surgery (Figure 1F). Both patients were considered at high risk for traditional surgery by the Heart Team. Thus, a Neochord procedure and pulmonary resection combined procedure was planned. Through a left thoracotomy and a postero-lateral left ventriculotomy, firstly four Gore-tex neochords were implanted on the posterior leaflet; secondly an inferior left lobectomy was performed for the youngest man and a resection of three nodules for the oldest one. Total operating time were 120 and145 minute, respectively. At the final intra-operative TEE, no regurgitation was detected (Figure 2). At 24 months no more than trivial to mild regurgitations is present in both patient and the oncological follow-up is negative. 

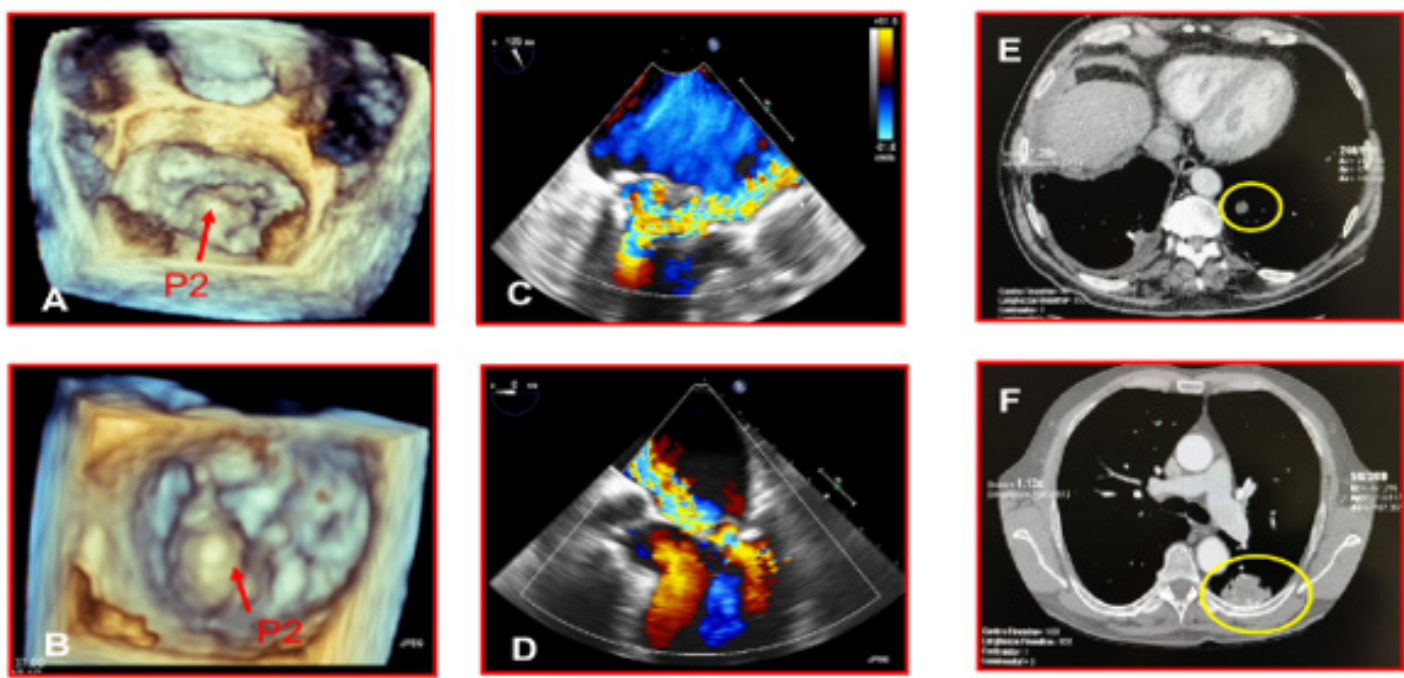

Figure 1: 3D transesophageal (TEE) and 2D transthoracic echocardiography (TTE) view of the P2 segment prolapse in patient $\mathrm{A}(\mathrm{A}$ and $\mathrm{C})$ and patient $\mathrm{B}(\mathrm{B}$ and $\mathrm{D})$. Pre-operative CT scan: metastatic left lobe lesion $(\mathrm{E})$ and left adenocarcinoma (F).
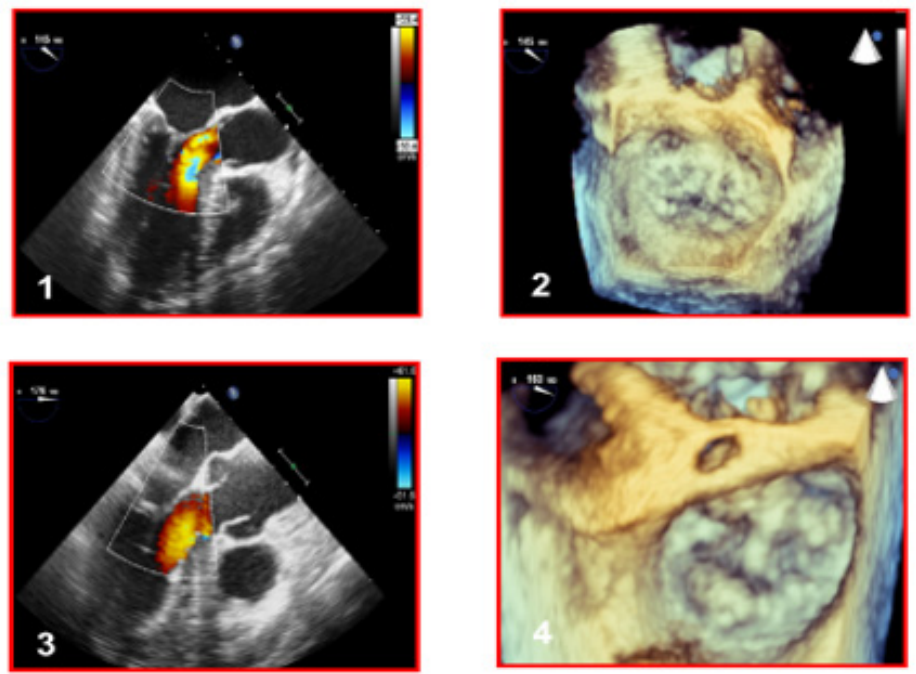

Figure 2: The final intra-operative 3D transesophageal (TEE) and 2D transthoracic echocardiography (TTE) view: no more mitral regurgitation in patient $\mathrm{A}(1$ and 2$)$ and patient $\mathrm{B}$ ( 3 and 4$)$.

\section{Conclusion}

These cases demonstrate the feasibility of combined beating heart surgery to treat structural mitral regurgitation and pulmonary lobectomy or atypical resection to treat malignancy throughout the same access.

\section{References}

1. Seeburger J, Rinaldi M, Nielsen SL, Salizzoni S, Lange R, et al. (2014) Offpump transapical implantation of artificial neo-chordae to correct mitral regurgitation: the TACT Trial (Transapical Artificial Chordae Tendinae) proof of concept. J Am Coll Cardiol 63(9): 914-919.
2. Colli A, Manzan E, Rucinskas K, Janusauskas V, Zucchetta F, et al. (2015) Acute safety and efficacy of the Neochord procedure. Interact CardioVasc Thorac Surg 20(5): 575-581.

3. Salizzoni S, Marro M, Rovera C, Speziali G, Rinaldi M (2017) Off-Pump NeoChord Mitral Valve Repair to Simultaneously Treat Posterior Leaflet Prolapse and Systolic Anterior Motion. Ann Thorac Surg 103(1): e29-e30.

4. Albertini A, Amoncelli E, Piccinini L, Caprili L (2018) Combined offpump minimally invasive coronary artery bypass grafting and mitral valve repair with NeoChord via a left anterolateral small thoracotomy. Interact Cardiovasc Thorac Surg 26(3): 525-526. 


\section{ISSN: 2574-1241}

DOI: 10.26717/BJSTR.2019.17.003037

Matteo Marro. Biomed J Sci \& Tech Res

(C) (P) This work is licensed under Creative

Submission Link: https://biomedres.us/submit-manuscript.php

$\begin{array}{ll}\text { BIOMEDICAL } & \text { Assets of Publishing with us } \\ \text { RESEARCHES } & \text { - Global archiving of articles } \\ & \text { - Immediate, unrestricted online access } \\ & \text { - Rigorous Peer Review Process } \\ \end{array}$

